\title{
Secondary Metabolites from an Infusion of Lippia gracilis Schauer Using the LC-DAD-SPE/NMR Hyphenation Technique
}

\author{
Valéria R. S. Moraes, ${ }^{* a, b}$ Sérgio S. Thomasi, ${ }^{b, c}$ Ricardo F. Sprenger ${ }^{b}$ Vilma M. J. Prado, ${ }^{a}$ \\ Elizangela M. O. Cruz, ${ }^{d}$ Quezia B. Cass, ${ }^{b}$ Antônio G. Ferreira ${ }^{b}$ and Arie F. Blank ${ }^{d}$ \\ ${ }^{a}$ Departamento de Química, Universidade Federal de Sergipe, Av. Marechal Rondon s/n, \\ 49100-000 São Cristovão-SE, Brazil \\ ${ }^{b}$ Departamento de Química, Universidade Federal de São Carlos, Rodovia Washington Luiz, \\ km 235, 13565-905 São Carlos-SP, Brazil \\ 'Departamento de Química, Universidade Federal de Lavras, Av. Doutor Sylvio Menicucci, \\ 1001, Kennedy 37200-000 Lavras-MG, Brazil \\ ${ }^{d}$ Departamento de Agronomia, Universidade Federal de Sergipe, Av. Marechal Rondon s/n, \\ 49100-000 São Cristovão-SE, Brazil
}

\begin{abstract}
The genus Lippia comprises approximately 200 species of herbs, shrubs and small trees, distributed throughout the South and Central America and tropical Africa. The species Lippia gracilis Schauer is an endemic aromatic plant of the Brazilian Northeast normally found in the states of Bahia, Sergipe and Piauí. The traditional communities of Caatinga, a semi-arid region of the Brazilian Northeast, use its leaves to treat throat and mouth infections, cutaneous diseases, ulcers, vagina disorders, acne, Pityriasis alba, dandruff, burns, wounds, sinusitis, bronchitis, nasal congestion, headache, jaundice and paralysis. Considering that the main investigations into the L. gracilis Schauer species are focused on its volatile constituents, in this report, we describe the isolation, by liquid chromatography with diode array detector-solid phase extraction/nuclear magnetic resonance (LC-DAD-SPE/NMR), of five flavonoids besides free and glycosidically bound carvacrol from an infusion of the leaves of a genotype of this species.
\end{abstract}

Keywords: Lippia gracilis Schauer, infusion, LC-DAD-SPE/NMR, flavonoids, carvacrol

\section{Introduction}

Brazilian plants have a great potential to be explored because, for many of them, there is little or no knowledge of their chemical compositions. ${ }^{1}$ Lippia gracilis Schauer (Verbenaceae) is a species that is included in this group once, to our knowledge, there is only one report about its non-volatile constituents, ${ }^{2}$ while most reports are focused on studies on the composition of essential oils and their biological activities. ${ }^{3-21}$

The genus Lippia comprises approximately 200 species of herbs, shrubs and small trees, distributed throughout the South and Central America countries and tropical Africa. ${ }^{22}$ The species L. gracilis Schauer is an endemic aromatic plant to the Brazilian Northeast normally found in the states of Bahia, Sergipe and Piauí. The traditional communities

*e-mail: valrsmoraes@uol.com.br of Caatinga, a semi-arid region of the Brazilian Northeast, use its leaves to treat throat and mouth infections, cutaneous diseases, ulcers, vagina disorders, acne, Pityriasis alba, dandruff, burns, wounds, sinusitis, bronchitis, nasal congestion, headache, jaundice and paralysis. ${ }^{23-25}$

Although there is little knowledge about the non-volatile constituents of L. gracilis, there are several phytochemical studies describing the isolation of various compounds from other species of this genus, including iridoid glucosides, phenylethanoid glucosides, phenylpropanoids, triterpenes saponins, flavonoids, naphthoquinones, flavonoids glucosides, lignans, sesquiterpenes and triterpenes. ${ }^{3-24}$

Previous chemical investigations into the $L$. gracilis Schauer species are focused on its volatile constituents where thymol and carvacrol, which showed strong antimicrobial activity against fungi and bacteria, are the main components. ${ }^{12}$ The chemical composition of the volatile compounds shows quantitative variations of the 
major components, probably due to genetic conditions depending on the location and conditions under which the plant is grown.

Another study evaluated the chemical composition of essential oils extracted from two different locations of the Caatinga area in the Pernambuco State, Brazil (Buíque and Ouricuri). It was demonstrated that carvacrol and $p$-cimene are the major constituents of the essential oil from Buíque, while thymol, $\gamma$-terpinene and 4-methoxy-acetophenone predominated in the samples from Ouricuri. ${ }^{10}$ In another study, the composition of essential oils of L. gracilis from other three states of northeastern Brazil (Ceará, Piauí and Sergipe) was analyzed, and it was demonstrated that thymol and $p$-cimene predominate in the samples from Ceará ${ }^{15}$ and Sergipe, ${ }^{9}$ while carvacrol and $p$-cimene predominate in the sample from Piauí. ${ }^{16}$

The literature only reports one study on the isolation of fixed constituents from the methanolic extract from the leaves of L. gracilis Schauer, which presented the isolation of the known flavanone: naringenin. ${ }^{2}$ Two other works only show the characterization of teas and methanolic extracts from L. gracilis Schauer genotypes cultivated in the rural campus of the Federal University of Sergipe and originated from the states of Sergipe and Bahia (Brazil) by liquid chromatography with diode array detector (LC-DAD) combined with chemometric analysis. ${ }^{22,26}$

In view of the above, in this study, we report the application of the LC-DAD-SPE/NMR (LC-DAD-solid phase extraction/nuclear magnetic resonance) hyphenation technique to isolate and identify some of the constituents of infusions of the leaves of a genotype of $L$. gracilis Schauer.

LC-DAD-SPE/NMR is a hyphenated technique that allows the chromatographic peaks to be automatically trapped on SPE cartridges, making multiple trappings possible, which results in a significant increase in the amount of isolated substances, facilitating the NMR analyses. ${ }^{27}$

This technique is very useful mainly when we are interested in discovering the components present in a mixture, even those in smaller quantities, avoiding the need to isolate them previously by open column chromatography techniques, which would be more time-consuming. Furthermore, a smaller sample handling occurs, avoiding the possibility of generating artifacts by oxidations, solvolysis, and thermal or photochemical degradation. ${ }^{28,29}$

\section{Experimental}

\section{General experimental procedures}

The analyses were carried out using an Agilent liquid chromatographic system (1200 series, Agilent
$\mathrm{GmbH}$ ) equipped with a quaternary pump (G1311A) and a degasser (G1322A) operating at $1.0 \mathrm{~mL} \mathrm{~min}^{-1}$, a variable wavelength diode array detector (G1315D), an autosampler (G1329A), and an automatic cartridge exchanger (Bruker Biospin GmbH). The LC system was controlled by the HyStar 2.3 software (Bruker). A Knauer (K120 Knauer Smartline Pump Control 100, Bruker Daltonik GmbH@, V01.11) makeup pump diluted the post column flow with water before the peaks were trapped using a Prospekt 2 SPE unit.

The 1D and 2D NMR spectra of the isolated compounds were acquired at $299 \mathrm{~K}$ with the use of a Bruker Avance III instrument (14.1 Tesla, Ultrashield Plus ${ }^{\circledR}$ ) fitted with an automatic sample changer and a triple resonance cryoprobe inverse of $5 \mathrm{~mm}\left({ }^{1} \mathrm{H} /{ }^{13} \mathrm{C} /{ }^{15} \mathrm{~N}\right)$ with $\mathrm{z}$-field gradient. Data collection and processing were carried out using the Bruker software Topspin 3.2 version. Each ${ }^{1} \mathrm{H}$ NMR spectrum obtained was recorded using 1D NOESY (nuclear Overhauser effect spectroscopy) pulse sequence with double presaturation (HDO and deuterated methanol) acquired with 32 scans; acquisition time of $2.7 \mathrm{~s}$; relaxation delay of 2.4 s; 4 dummy scans and 65,536 data points. Spectra were processed without the use of apodization function, $\mathrm{TD}=65,536$ and using 32,768 data points. COSY (correlation spectroscopy) spectra were acquired with 16 scans; 8 dummy scans; TDF1 $=256$ and TDF2 $=4,096$. Heteronuclear single quantum correlation (HSQC) spectra were acquired with 32 scans; 16 dummy scans; TDF1 = 256 and TDF2 $=4,096$. Heteronuclear multiple bond correlation (HMBC) spectra were acquired with 200 scans; 16 dummy scans; TDF1 = 281, TDF2 = 4,096 and optimized for ${ }^{n} J_{\mathrm{C}, \mathrm{H}}=8 \mathrm{~Hz}$. All the 2D spectra were processed without the use of apodization function, with number of points in F1 domain of 1,024; number of points in F2 domain of 4,096 and using linear prediction in F1. The spectra were referenced to tetramethylsilane (TMS) at $0.0 \mathrm{ppm}$ and the chemical shifts of all hydrogens and carbons were reported using $\delta$ values.

The mass spectrometry experiments were carried out using an ESI-ITMS Bruker ${ }^{\mathrm{TM}}$ Esquire 6000 equipment and the data processing was accomplished with the DataAnalysis software. For sample preparation and LC analyses, LC-grade solvents such as acetonitrile (JT Baker, Philipsburg, PA, USA) and methanol (JT Baker, Philipsburg, PA, USA) were used. Deionised water was purified by a Milli-Q ${ }^{\circledR}$ system (Millipore, São Paulo, SP, Brazil). All solvents were filtered through nylon $0.45 \mu \mathrm{m}$ membranes (MFS) and degassed by ultrasonic bath before use. The compounds were trapped in HySphere Resin GP SPE cartridges $(10 \times 2 \mathrm{~mm}, 10 \mu \mathrm{m}$ spherical polydivinylbenzene stationary phase) based on UV absorption threshold method. 
Plant material

Leaves of the L. gracilis genotype called 110 (cultivated without irrigation) originated from the state of Sergipe (11 ${ }^{\circ} 19^{\prime} 21.1^{\prime \prime} \mathrm{S} ; 37^{\circ} 55^{\prime} 14.9^{\prime}$ 'W) and cultivated at the Experimental Farm of the Rural Campus of the Federal University of Sergipe (UFS) were collected in January 2010. The leaves were identified by PhD Ana Paula Prata, and a voucher specimen was deposited at the Federal University of Sergipe Herbarium, Department of Biology under number 14732. The material was dried in a forced air circulation oven at $40{ }^{\circ} \mathrm{C}$ for 5 days..$^{19,26}$

\section{Sample preparation}

The tea was prepared by the infusion method where $200 \mathrm{~mL}$ of Milli-Q water at $94^{\circ} \mathrm{C}$ (heated in a microwave oven) were added to 2.0 grams of leaves and it was left to rest for 10 minutes. This procedure was performed three times. Then, the tea was filtered through analytical paper, frozen and lyophilized (at the temperature of $-54{ }^{\circ} \mathrm{C}$ and pressure of $79 \mu \mathrm{m} \mathrm{Hg}$ ), providing $527.9 \mathrm{mg}$ of extract. ${ }^{26}$

\section{LC conditions used in LC-DAD-SPE}

For the chromatographic separations, solutions containing $31.9 \mathrm{mg} \mathrm{mL}^{-1}$ of sample were prepared in methanol and ultrapure water $(8: 2 \mathrm{v} / \mathrm{v})$ with 4 drops of triflouoroacetic acid (Aldrich); subsequently, it was filtered through a PVDF membrane syringe filter $(25 \mathrm{~mm}$, $0.45 \mu \mathrm{m}$, Tedia, Brazil) prior to the LC analyses. The chromatographic separations were carried out using an analytical Eurobond Prontosil $\mathrm{C}_{18}$ Luna $^{\circledR}$ column $(125 \times 4.0 \mathrm{~mm}, 5 \mu \mathrm{m})$ with $20 \mu \mathrm{L}$ injection volumes. To isolate compounds $\mathbf{1}$ and $\mathbf{2}$, a binary eluent consisting of an aqueous solution of trifluoroacetic acid (TFA, Tedia, Brazil) $0.05 \%(\mathrm{v} / \mathrm{v})(\mathrm{A})$ and $\mathrm{MeOH}(\mathrm{B})$ at $1.0 \mathrm{~mL} \mathrm{~min}^{-1}$ was used with a gradient as follow: 5-28\% (B) in $14 \mathrm{~min}, 28-34.5 \%$ (B) in $26 \mathrm{~min}, 34.5-100 \%$ (B) in 2 min and, maintained at $100 \%$ for 5 min (clean-up) before returning to the initial conditions in $2 \mathrm{~min}$ and, then, conditioning for a further $5 \mathrm{~min}$. The elution was monitored based on UV absorption at $206 \mathrm{~nm}$ and, for each chromatographic peak, a total of twenty-five trappings were made. To isolate compounds $\mathbf{3}$ to 7, a binary eluent consisting of an aqueous solution of TFA $0.05 \%(\mathrm{v} / \mathrm{v})(\mathrm{A})$ and ACN with $0.05 \%$ aqueous TFA (B) at $1.0 \mathrm{~mL} \mathrm{~min}^{-1}$ was used. The gradient employed was: $5-13 \%$ (B) in $5 \mathrm{~min}, 13-28 \%$ (B) in $15 \mathrm{~min}, 28-100 \%$ (B) in $15 \mathrm{~min}$, maintained at $100 \%$ (B) for 5 min (clean-up). The initial condition was achieved in $1 \mathrm{~min}$ and maintained for conditioning for a further $4 \mathrm{~min}$. The elution profile was monitored based on UV absorption at $200 \mathrm{~nm}$ and a total of thirty trappings were carried out. In the end of each chromatographic analysis, the cartridges were dried with nitrogen gas for 30 minutes; the compounds were eluted with methanol- $d_{4}$ (Deutero, 99.8\%) and transferred to NMR tubes (Bruker, $3 \mathrm{~mm}$ o.d.) in order to be analyzed.

\section{Results and Discussion}

Considering that one of the main motivations for studying a plant comes from its popular indication for some type of illness, and/or due to any scientifically-proven biological activity, the time and dedication spent isolating the active compounds using open column chromatography may not be worth it, once it commonly results in the isolation of known compounds. ${ }^{30}$ Thus, for gaining chemical information with productivity, LC-DAD-SPE/NMR was used for the chemical characterization of the infusion of L. gracilis Schauer genotype 110 .

The chromatographic conditions used for the isolation of compounds were based on the chromatographic profile as previously published by our research group, ${ }^{26}$ with minor modifications in order to optimize the trapping of the compounds, with high throughput.

To meet this end, the obtained chromatogram profile was divided into two sections; at first, our interest was focused in the two most intense peaks with retention times of 40 and 50 minutes. The substitution of formic acid aqueous solution $0.5 \%(\mathrm{v} / \mathrm{v})$ as eluent (A) for TFA solution affected the retention times of both peaks and they elluted before $30 \mathrm{~min}$. The gradient profile of the organic modifier $\mathrm{MeOH}(\mathrm{B})$ was, thus, adjusted in order to trap orientin $\left(\mathbf{1}, t_{\mathrm{R}}=27.0 \mathrm{~min}\right.$, $600 \mu \mathrm{g}),{ }^{31,32}$ and isoorientin $\left(2, t_{\mathrm{R}}=29.0 \mathrm{~min}, 500 \mu \mathrm{g}\right)^{31,32}$ flavonoids.

For the second section of the original chromatographic profile with compounds that eluted after 50 minutes, ${ }^{26}$ the exchange of methanol as the modifier for acetonitrile led to higher resolution which improved the trapping process. At the developed chromatographic conditions, it was possible to trap luteolin 4'-O- $\beta$-glucopyranoside (3, $\left.t_{\mathrm{R}}=17.5 \mathrm{~min}, 700 \mu \mathrm{g}\right),{ }^{33,34}$ carvacrol $2-O$ - $\beta$-glucopyranoside $\left(4, t_{\mathrm{R}}=22.7 \mathrm{~min}, 500 \mu \mathrm{g}\right),{ }^{35} 5,7,3^{\prime}, 5^{\prime}$ '-tetrahydroxy flavanone $\left(\mathbf{5}, t_{\mathrm{R}}=23.2 \mathrm{~min}, 300 \mu \mathrm{g}\right),{ }^{36}$ naringenin $\left(\mathbf{6}, t_{\mathrm{R}}=25.4 \mathrm{~min}\right.$, $500 \mu \mathrm{g})^{2}$ and carvacrol $\left(7, t_{\mathrm{R}}=29.5 \mathrm{~min}, 600 \mu \mathrm{g}\right){ }^{31}$

The SPE trapping method chosen was the UV absorption threshold, which selects the bands based on the intensity of their UV absorptions, this approach minimizes the errors caused by the slight variation in the retention time of the selected bands during the chromatographic runs.

The chemical structures of the seven out of ten isolated compounds were determined by analysis of 1D (using 
1D NOESY with double saturation for solvent signal suppression) and 2D NMR (COSY, HSQC and HMBC) data as well as by comparing them with data reported in the literature.

The ${ }^{1} \mathrm{H}$ NMR spectrum of compound 1 showed signals of aromatic ring $\mathrm{B}$ at $\delta 7.56(\mathrm{~s}), 7.52(\mathrm{~d}, J=8.1 \mathrm{~Hz})$ and $6.91(\mathrm{~d}, J=8.1 \mathrm{~Hz}$ ) corresponding to hydrogens on C-2', 6' and 5', respectively. A doublet at $\delta 4.98(J=9.8 \mathrm{~Hz})$ and two singlets at $\delta 6.27$ and 6.54 were assigned to the anomeric hydrogen (H-1") of the glycosyl unit attached to $\mathrm{C}-8$ and to the hydrogens on C-6 and C-3, respectively, confirming the flavone skeleton. The location at C-8 of the sugar moiety was established on the basis of the cross peak from H-1" $(\delta 4.98)$ to C-7 $(\delta 165.9), \mathrm{C}-8(\delta 106.6)$ and C-9 ( $\delta$ 159.4) in the HMBC spectrum.

The ${ }^{1} \mathrm{H}$ NMR spectrum of compound 2 was similar to that of orientin, showing signals for three aromatic hydrogens of the typical ABX system (ring B) at $\delta 7.38$ (s), $7.39(\mathrm{~d}, J=8.3 \mathrm{~Hz})$ and $6.91(\mathrm{~d}, J=8.3 \mathrm{~Hz})$ corresponding to hydrogens on C-2', 6' and 5', respectively. A doublet at $\delta 4.90(J=9.5 \mathrm{~Hz})$ and two singlets at $\delta 6.51$ and 6.56 were assigned to the anomeric hydrogen (H-1") of the glycosyl unit attached to C-6 and to the hydrogens on C-8 and C-3, respectively, typical of a flavone skeleton. In this case, the location of the sugar moiety was established at C-6 on the basis of the cross peak from $\mathrm{H}-1$ " $(\delta 4.90)$ to $\mathrm{C}-7$ ( $\delta$ 166.6), C-6 $(\delta$ 110.4) and C-5 ( $\delta$ 163.4) in the HMBC spectrum.

Based on these data and on those obtained by 2D NMR (tables presented in the Supplementary Information section), it was possible to identify the compounds as 3', 4', 5,7-tetrahydroxyflavone-8-glucoside (orientin) and 3',4',5,7-tetrahydroxyflavone-6-glucoside (isoorientin). ${ }^{31,32}$

To further furnish insight in the chemical structures of compounds $\mathbf{1}$ and $\mathbf{2}$ they were also submitted to analysis by (-)ESI-ITMS ${ }^{2}$ (electrospray ionization-ion trap tandem mass spectrometry). For $\mathbf{1}$ and $\mathbf{2}$, the $\mathrm{MS}^{2}$ spectra presented the product ions $m / z 357[\mathrm{M}-\mathrm{H}-90]^{-}$and $m / z 327$ $[\mathrm{M}-\mathrm{H}-120]^{-}$, which are representative of ${ }^{0,3} \mathrm{X}$ and ${ }^{0,2} \mathrm{X}$ glucose cross-ring cleavage. The differentiation of both is based on the intensity of these ions: for orientin, the base peak is $m / z$ 327, while for isoorientin, it is $m / z 357 .{ }^{37}$ Furthermore, the isoorientin fragmentation spectrum reveals the loss of water $(\mathrm{m} / \mathrm{z}, 429$ and 411$)$ typical of C-6 and absent from C-8 flavones. ${ }^{38}$

The ${ }^{1} \mathrm{H}$ NMR spectrum of compound 3 showed a singlet at $\delta$ 6.61, which presented an HSQC correlation $(\mathrm{H}-\mathrm{C}$ directly bonded) with a carbon at $\delta 106.4$, which is typical of the flavone skeleton. Furthermore, this spectrum displayed signals for three aromatic hydrogens of the typical ABX system (ring B) at $\delta 7.46(\mathrm{~m}), 7.47(\mathrm{~d}, J=8.4 \mathrm{~Hz})$ and 7.33 (d, $J=8.4 \mathrm{~Hz}$ ) corresponding to hydrogens on C-2', 6' and
5', respectively. A meta-coupled AX system for H-6 and $\mathrm{H}-8$ (ring A) was confirmed by the two doublets at $\delta 6.22$ $(J=2.1 \mathrm{~Hz})$ and $6.46(J=2.1 \mathrm{~Hz})$, respectively. A doublet at $\delta 4.94(J=7.5 \mathrm{~Hz})$ was assigned to the anomeric hydrogen (H-1") of a glycosyl $O$-linked to the C-4' position in the ring $\mathrm{B}$, which was established on the basis of the cross peak from H-1" $(\delta 4.94)$ to C-4' $(\delta 151.2)$ in the HMBC spectrum. These results aided by 2D NMR data (see Supplementary Information) allowed the identification of this compound as luteolin-4'-O- $\beta$-glucopyranoside. ${ }^{33,34}$

The ${ }^{1} \mathrm{H}$ NMR spectra of compounds $\mathbf{4}$ and $\mathbf{7}$ were very similar, showing characteristic signals of carvacrol 2- $O-\beta$ glucopyranoside and carvacrol, respectively. The presence of an isopropyl group was confirmed by septets at $\delta 2.84$ (4: $1 \mathrm{H}, J=6.9 \mathrm{~Hz})$ and $2.76(7: 1 \mathrm{H}, J=7.0 \mathrm{~Hz})$ and doublets at $\delta 1.22\left(4: 2 \mathrm{CH}_{3}, J=6.9 \mathrm{~Hz}\right)$ and $1.19\left(7: 2 \mathrm{CH}_{3}, J=7.0 \mathrm{~Hz}\right)$ in each spectrum. In addition, two singlets at $\delta 2.22$ (4) and 2.12 (7) corresponding to the methyl group attached to the benzene ring were also observed in each compound. Furthermore, each spectrum showed signals for three aromatic hydrogens of the typical ABX system. For the compound 4, these signals appeared at $\delta 7.01(\mathrm{~d}, J=8.0 \mathrm{~Hz}$, H-6), 7.00 (d, $J=1.8 \mathrm{~Hz}, \mathrm{H}-3)$ and $6.78(\mathrm{dd}, J=8.0$ and $1.8 \mathrm{~Hz}, \mathrm{H}-5)$, and for the compound 7 at $\delta 6.93$ (dd, $J=7.4$ and $0.5 \mathrm{~Hz}, \mathrm{H}-6), 6.59$ (dd, $J=7.4$ and $1.7 \mathrm{~Hz}, \mathrm{H}-5)$ and $6.61(\mathrm{~d}, J=1.7 \mathrm{~Hz}, \mathrm{H}-3)$. A doublet at $\delta 4.86(J=7.6 \mathrm{~Hz})$ was assigned to the anomeric hydrogen (H-1') of a glycosyl $O$-linked to the $\mathrm{C}-2$ position in the benzene ring, which was confirmed on the basis of the cross peaks from $\mathrm{H}-1$ ' $(\delta$ 4.86), H-6 ( $\delta$ 7.01) and H-7 $(\delta$ 2.22) to C-2 $(\delta$ 158.5) in the HMBC spectrum. On the basis of these analyses and those from the 2D NMR data (see Supplementary Information), the structures of compounds $\mathbf{4}$ and $\mathbf{7}$ were confirmed as being carvacrol 2-O- $\beta$-glucopyranoside and carvacrol, respectively. ${ }^{31,35}$

The ${ }^{1} \mathrm{H}$ NMR spectra of compounds $\mathbf{5}$ and $\mathbf{6}$ displayed the diastereotopic effect due to two methylene hydrogens on C-3, which are adjacent to the chiral center at C-2 typical of a flavanone skeleton. Thus, these methylene hydrogens appeared as double doublets at $\delta 3.07(J=17.1$ and $12.7 \mathrm{~Hz})$ and $2.70(J=17.1$ and $3.1 \mathrm{~Hz})$ for compound $\mathbf{5}$, and at $\delta 3.11$ $(J=17.1$ and $13.0 \mathrm{~Hz})$ and $2.69(J=17.1$ and $3.0 \mathrm{~Hz})$ for compound 6 . The hydrogen on $\mathrm{C}-2$ also appeared as double doublets at $\delta 5.28(J=12.7$ and $3.1 \mathrm{~Hz})$ and $5.34(J=13.0$ and $3.0 \mathrm{~Hz}$ ) for compounds $\mathbf{5}$ and $\mathbf{6}$, respectively. Typical signals for meta-coupled AX systems, for these two compounds, appeared in the same chemical shift as two doublets at $\delta 5.87$ $(J=2.2 \mathrm{~Hz})$ and $5.89(J=2.2 \mathrm{~Hz})$ for $\mathrm{H}-6$ and $\mathrm{H}-8$ (ring A), respectively. For the compound $\mathbf{5}$, the aromatic hydrogens for ring $\mathrm{B}$ appeared in the ${ }^{1} \mathrm{H}$ NMR spectrum as two doublets at $\delta 6.79\left(J=1.7 \mathrm{~Hz}, \mathrm{H}-2^{\prime} / \mathrm{H}-6^{\prime}\right)$ and 6.91 ( $\left.J=1.7 \mathrm{~Hz}, \mathrm{H}-4^{\prime}\right)$. 

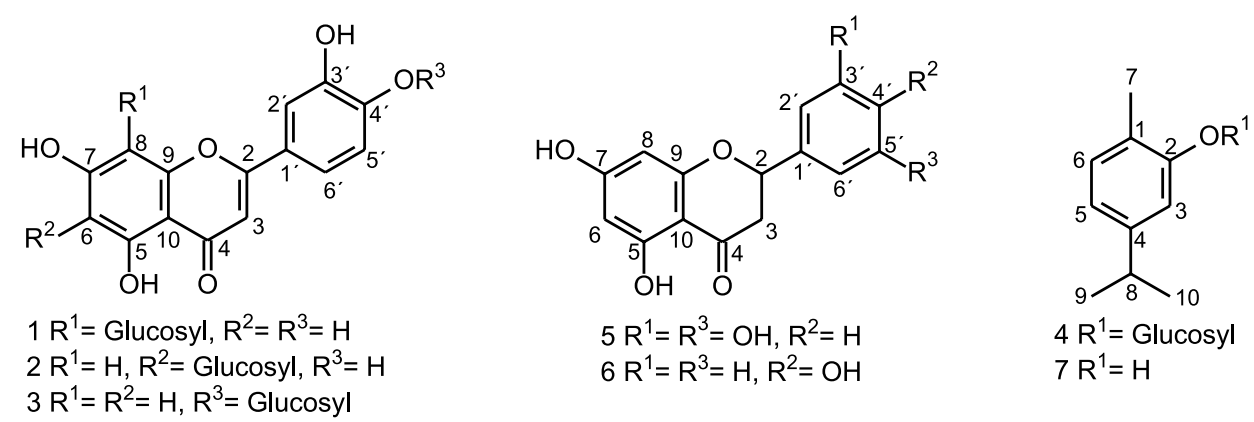

Figure 1. Chemical structures of the compounds isolated from Lippia gracilis Schauer.

On the other side, an AA'XX' system was observed for ring B for compound $\mathbf{6}$, which was confirmed by the presence of two doublets at $\delta 7.32\left(J=8.7 \mathrm{~Hz}, \mathrm{H}-2^{\prime} / 6^{\prime}\right)$ and $6.82(J=8.7 \mathrm{~Hz}$, H-3'/5'). These results combined with 2D NMR data (see Supplementary Information) allowed the identification of compounds 5 and $\mathbf{6}$ as 5,7,3',5'-tetrahydroxy flavanone and naringenin, respectively., 2,36

\section{Conclusions}

This is the second report about fixed constituents from L. gracilis Schauer. Herein, we describe the isolation and complete characterization of seven out of ten trapped compounds by LC-DAD-SPE/NMR from the infusion of the leaves of genotype 110 of this species: orientin $\mathbf{1}$, isoorientin $\mathbf{2}$, luteolin 4 '- $O-\beta$-glucopyranoside luteolin $\mathbf{3}$, carvacrol 2-O- $\beta$-glucopyranoside 4, 5,7,3',5'-tetrahydroxy flavanone 5 , naringenin $\mathbf{6}$, and carvacrol 7 .

Furthermore, to our knowledge, the compounds $\mathbf{1}$ to 5 have never been reported for this genus. In this way, the use of the LC-DAD-SPE/NMR approach allowed greater knowledge about the chemical composition of the compounds present in the infusions of $L$. gracilis with only 45 hours of chromatographic run time.

\section{Supplementary Information}

The tables containing the NMR data, ${ }^{1} \mathrm{H}$ NMR and UV spectra (acquired using DAD) for each compound isolated and identified are available free of charge at http://jbcs.sbq. org.br as PDF file.

\section{Acknowledgments}

The authors thank the Brazilian funding agencies FAPITEC/SE, FAPESP (2011/11021-3 and 201301710-1), CNPq and CAPES for their financial support and scholarships, as well as INCT-Biorational Control of Plague Insects and Northeast Biotechnology Network (RENORBIO).

\section{References}

1. Cecílio, A. B.; Faria, D. B.; Oliveira, P. C.; Caldas, S.; Oliveira, D. A.; Sobral, M. E. G.; Duarte, M. G. R.; Moreira, C. P. S.; Silva, C. G.; Almeida, V. L.; J. Ethnopharmacol. 2012, 141, 975.

2. Guimarães, A. G.; Gomes, S. V. F.; Moraes, V. R. S.; Nogueira, P. C. L.; Ferreira, A. G.; Blank, A. F.; Santos, A. D. C.; Viana, M. D.; Silva, G. H.; Quintans, L. J.; J. Nat. Med. 2012, 66, 428.

3. Pascual, M. E.; Slowing, K.; Carretero, E.; Mata, D. S.; Villar, A.; J. Ethnopharmacol. 2001, 76, 201.

4. Bitu, V.; Botelho, M. A.; Costa, J. G. M.; Rodrigues, F. F. G.; Veras, H. N. H.; Martins, K. T.; Lyra, A.; Coluchi, G. G.; Ruela, R. S.; Queiroz, D. B.; Siqueira, J. S.; Quintans, L. J.; Rev. Bras. Farmacogn. 2012, 22, 69.

5. Guilhon, C. C.; Raymundo, L. J. R. P.; Alviano, D. S.; Blank, A. F.; Arrigoni-Blank, M. F.; Matheus, M. E.; Cavalcanti, S. C. H.; Alviano, C. S.; Fernandes, P. D.; J. Ethnopharmacol. 2011, $135,406$.

6. Cavalcanti, S. C. H.; Niculau, E. S.; Blank, A. F.; Câmara, C. A. G.; Araújo, I. N.; Alves, P. B.; Bioresour. Technol. 2010, 101, 829.

7. Neto, R. M.; Matos, F. J. A.; Andrade, V. S.; Melo, M. C. N.; Carvalho, C. B. M.; Guimarães, S. B.; Pessoa, O. D. L.; Silva, S. L.; Silva, S. F. R.; Vasconcelos, P. R. L.; Rev. Bras. Farmacogn. 2010, 20, 261.

8. Mendes, S. S.; Bomfim, R. R.; Jesus, H. C. R.; Alves, P. B.; Blank, A. F.; Estevam, C. S.; Antoniolli, A. R.; Thomazzi, S. M.; J. Ethnopharmacol. 2010, 129, 391.

9. Teles, T. V.; Bonfim, R. R.; Alves, P. B.; Blank, A. F.; Jesus, H. C. R.; Quintans-Jr, L. J.; Serafini, M. R.; Bonjardim, L. R.; Araujo, A. A. S.; Afr. J. Biotechnol. 2010, 9, 8800.

10. Neves, I. A.; Oliveira, J. C. S.; Camara, C. A. G.; Schwartz, M. O. E.; J. Essent. Oil Res. 2008, 20, 157.

11. Lima, M. C. L.; Lemos, T. L. G.; Pessoa, O. D. L.; Santiago, G. M. P.; Matos, F. J. A.; Arriaga, A. M. C.; Oliveira, J. P. P.; Sant'ana, A. E. G.; Chem. Nat. Comp. 2008, 44, 254.

12. Albuquerque, C. C.; Camara, T. R.; Mariano, R. L. R.; Willadino, L.; Marcelino Júnior, C.; Ulisses, C.; Braz. Arch. Biol. Technol. 2006, 49, 527. 
13. Santiago, G. M. P.; Lemos, T. L. G.; Pessoa, O. D. L.; Arriaga, A. M. C.; Matos, F. J. A.; Lima, M. A. S.; Santos, H. C.; Lima, M. C. L.; Barbosa, F. G.; Luciano, J. H. S.; Silveira, E. R.; Menezes, G. H. A.; Nat. Prod. Commun. 2006, 1, 573.

14. Pessoa, O. D. L.; Carvalho, C. B. M.; Silvestre, J. O. V. I.; Lima, M. C. L.; Neto, R. M.; Matos, F. J. A.; Lemos, T. L. G.; Fitoterapia 2005, 76, 712.

15. Lemos, T. L. G.; Monte, F. J. Q.; Matos, F. J. A.; Alencar, F. W.; Craveiro, A. A.; Barbosa, R. C. S. B.; Lima, E. D.; Fitoterapia 1992, 63, 266.

16. Matos, F. J. A.; Plantas da Medicina Popular do Nordeste - Propriedades Atribuídas e Confirmadas, $1^{\mathrm{a}}$ ed.; Ed. UFC: Fortaleza, Brasil, 1999.

17. Melo, J. O.; Fachin, A.; Rizo, W. F.; Jesus, H. C. R.; ArrigoniBlank, M. F.; Alves, P. B.; Marins, M. A.; França, S. C.; Blank, A. F.; Genet. Mol. Res. 2014, 13, 2691.

18. Cruz, E. M. O.; Costa-Junior, L. M.; Pinto, J. A. O.; Santos, D. A.; Araujo, S. A.; Arrigoni-Blank, M. F.; Bacci, L.; Alves, P. B.; Cavalcanti, S. C. H.; Blank, A. F.; Vet. Parasitol. 2013, 195, 198.

19. Cruz, E. M. O.; Pinto, J. A. O.; Fontes, S. S.; Arrigoni-Blank, M. F.; Bacci, L.; Jesus, H. C. R.; Santos, D. A.; Alves, P. B.; Blank, A. F.; Sci. World J. 2014, $2014,1$.

20. Melo, J. O.; Bitencourt, T. A.; Fachin, A. L.; Cruz, E. M. O.; Jesus, H. C. R.; Alves, P. B.; Arrigoni-Blank, M. F.; Franca, S. C.; Beleboni, R. O.; Fernandes, R. P. M.; Blank, A. F.; Scher, R.; Acta Tropica 2013, 128, 110.

21. Carvalho, R. R. C.; Laranjeira, D.; Carvalho, F. J. L. S.; Souza, P. E.; Blank, A. F.; Alves, P. B.; Jesus, H. C. R.; Warwick, D. R. N.; Quim. Nova 2013, 36, 241.

22. Gomes, S. V. F.; Santos, A. D. C.; Moraes, V. R. S.; Martins, L. R. R.; Viana, M. D.; Blank, A. F.; Pereira-Filho, E. R.; Cass, Q. B.; Nogueira, P. C. L.; Alves, P. B.; Chromatographia 2010, 72,275 .

23. Lorenzi, H.; Matos, F. J. A.; Plantas Medicinais no Brasil: Nativas e Exóticas, 1ª ed.; Plantarum: São Paulo, Brazil, 2002.
24. Gomes, S. V. F.; Nogueira, P. C. L.; Moraes, V. R. S.; Ecletica Quim. 2011, 36, 64.

25. Albuquerque, U. P.; Medeiros, P. M.; Almeida, A. L. S.; Monteiro, J. M.; Lins, N. E. M. F.; Melo, J. G.; Santos, J. P.; J. Ethnopharmacol. 2007, 114, 325.

26. Prado, V. M. J.; Moraes, V. R. S.; Nogueira, P. C. L.; Cruz, E. M. O.; Blank, A. F.; Pereira-Filho, E. R.; Martins, L. R. R.; Quim. Nova. 2012, 35, 1814.

27. Lambert, M.; Stærk, D.; Hansen, S. H.; Sairafianpour, M.; Jaroszewski, J. W.; J. Nat. Prod. 2005, 68, 1500.

28. Clarkson, C.; Stærk, D.; Hansen, S. H.; Jaroszewski, J. W.; Anal. Chem. 2005, 77, 3547.

29. Xu, Y.-J.; Capistrano, I. R.; Dhooghe, L.; Foubert, K.; Lemière, F.; Maregesi, S.; Baldé, A.; Apers, S.; Pieters, L.; Planta Med. 2011, 77, 1139.

30. Jaroszewski, J. W.; Planta Med. 2005, 71, 691.

31. Wen, P.; Han, H.; Wang, R.; Wang, N.; Yao, X.; Asian J. Tradit. Med. 2007, 2, 149.

32. Burns, D. C.; Ellis, D. A.; March, R. E.; Magn. Res. Chem. 2007, 45, 835 .

33. Krenn, L.; Miron, A.; Pemp, E.; Petr, U.; Kopp, B.; J. Biosci. 2003, $58 C, 6$.

34. Patora, J.; Klimek, B.; Acta Pol. Pharm. 2002, 59, 139.

35. Kamel, M. S.; Assaf, M. H.; Hasanean, H. A.; Ohtani, K.; Kasai, R.; Yamasaki, K.; Phytochemistry 2001, 58, 1149.

36. Gohari, A. R.; Ostad, S. N.; Moradi-Afrapoli, F.; Malmir, M.; Tavajohi, S.; Akbari, H.; Saeidnia, S.; Sci. World J. 2012, 2012, 1.

37. Ferreres, F.; Silva, B. M.; Andrade, P. B.; Seabra, R. M.; Ferreira, M. A.; Phytochem. Anal. 2003, 14, 352.

38. Waridel, P.; Wolfender, J. L.; Ndjoko, K.; Hobby, K. R.; Major, H. J.; Hostettmann, K.; J. Chromatogr. A 2001, 926, 29.

Submitted: July 7, 2016

Published online: November 17, 2016 